\title{
DAMAGE DETECTION METHOD FOR SLEEPERS BASED ON VIBRATION PROPERTIES
}

\author{
Kodai Matsuoka ${ }^{1, a}$, Tsutomu Watanabe ${ }^{1}$ and Masamichi Sogabe \\ ${ }^{1}$ Railway Technical Research Institute, Railway Dynamics Division, 1858540 Kokubunji-shi, Tokyo, Japan
}

\begin{abstract}
In order to detect the damages of PC sleeper in the ballast track which cannot be inspected visually, the damage detection method using vibration mode characteristic of PC sleepers was developed. As a result of the vibration measurement test that conducted in parallel to the bending test, it was confirmed that natural frequencies begin to decrease when more than 1.2 times of the cracking load acted. In Addition, as the results of measurements PC sleepers with actual damages and measurements at the full-scale test rail line, 3rd mode natural frequency in which the effect of damage appears greatly and the variation of ballast does not affect is a suitable indicator for detection of the cracks. Furthermore, focusing on the application on the routine patrol, the high workability damage detection by single point measurement and simple signal processing was considered. As a result, it ca be confirmed that the same detection accuracy as the damage detection based on the multipoint measurement was securable.
\end{abstract}

\section{Introduction}

A huge number of PC sleepers have been continuously introduced into railway line in Japan since the 1950s. In general, although the durable life of the civil engineering concrete members is considered more than 50 years, it is also envisioned that the PC sleepers can be utilized more period effectively. Therefore, for sequentially replacement of existing PC sleepers according to its state, a technique to be able to evaluate the deterioration and damages of the PC sleeper appropriately is required.

One of the deterioration factors of PC sleepers is a mechanical factor. In particular, it is considering that the major factor is the impact load greatly exceeds the design load due to the wheel irregularities (wheel flat), rail irregularities and the rail joints, etc. Although such impact load is extremely rare, however if acting once, it cause yielding of steel members, residual displacement or residual cracking of concrete occur at the bottom of rail position and the top of middle as shown in Figure 1, and then, these damages also can lead to the loss of the bending strength according to the posterior circumstances. However, the visual confirmation of the damages through the daily inspections, such as routine patrol, is difficult even for fairly serious damages because the other than the top surface of the PC sleepers are buried in the ballast.

In this study, we reach a solution such problem by the abnormality detection using sensors. It should be noted that abnormality detection of the PC sleepers is different in nature from the abnormality detection such like bridges in terms of the damage level of the detection target. In case of PC sleepers, even if it alone has a state near the destruction, if made vertical force transmission and gauge

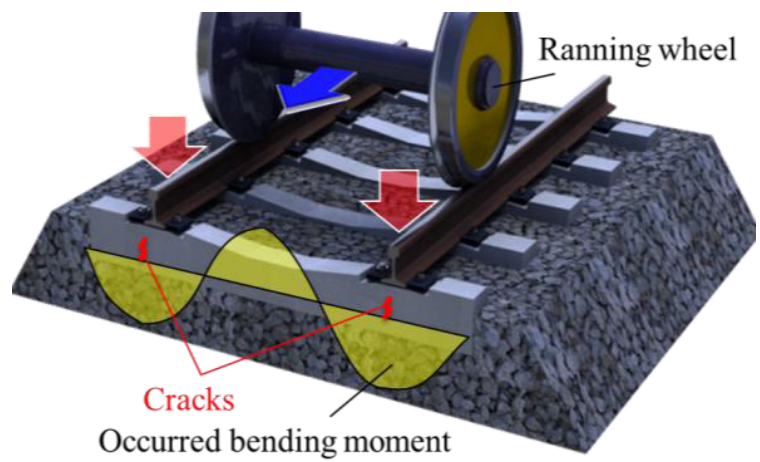

Figure 1. Caption of the Figure 1. Below the figure.

retention, it does not affect the driving safety and riding comfort of the train immediately. Therefore, with respect to the PC sleepers, the development of detection method which can determine the time for replacement directly has a higher demand than the methods for constantly monitoring or prediction based on minor damages such like wear or small cracks.

Based on the above background, in order to develop a damage detection method for the PC sleeper, focusing on its mode characteristics, this study conducted (1) to clarify the relation between the damage and the mode characteristics by loading test, (2) to clarify the impact of actual damages such like cracks etc. which have occurred through the operation period and the actual environment (boundary conditions) of rail and ballast on the mode characteristics, and (3) simplification of vibration measurement and signal processing with a view point of a practical use.

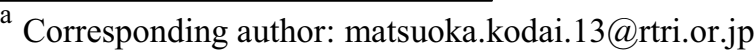


MATEC Web of Conferences

Table 1. List of Targeted PC sleepers

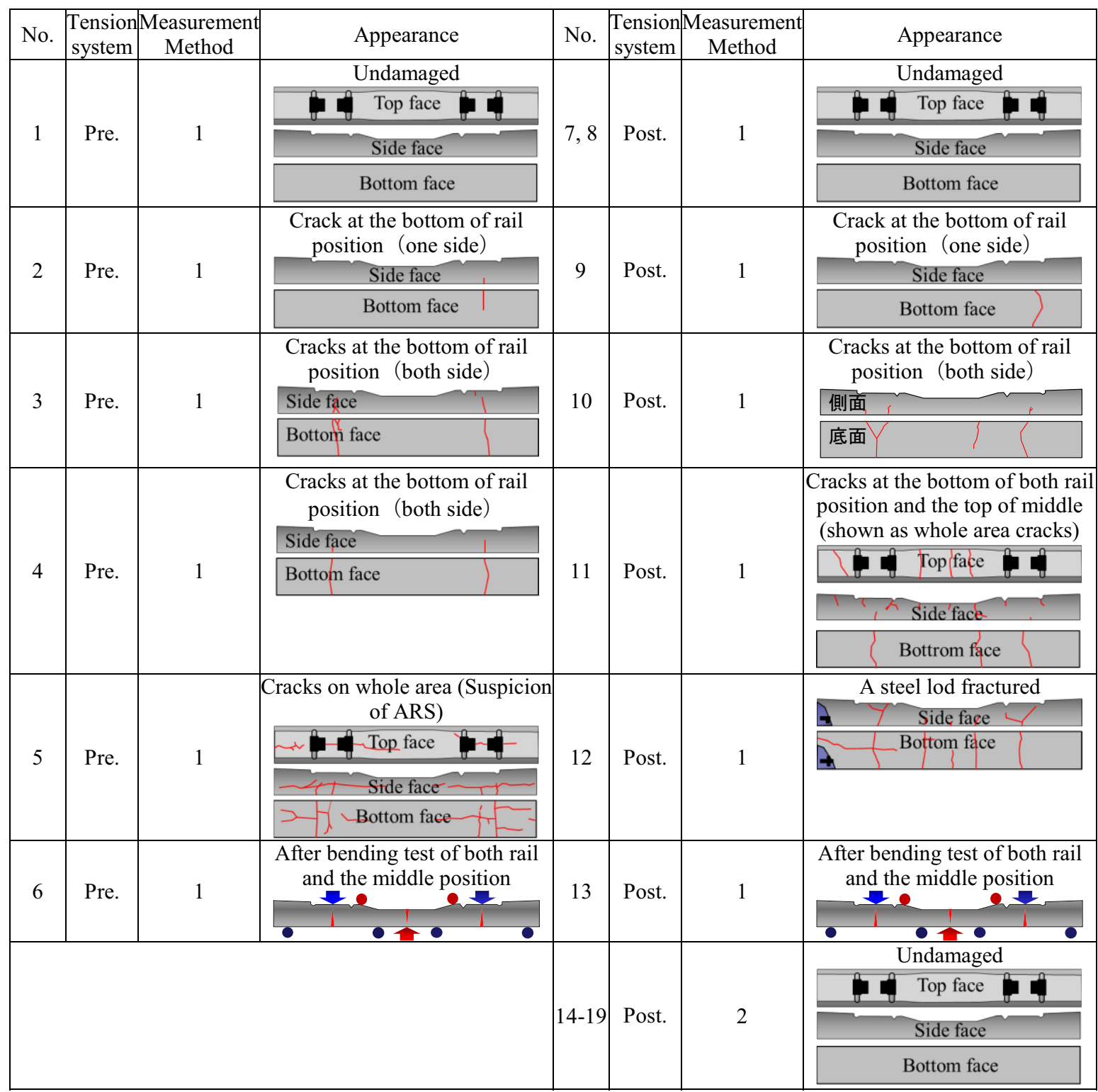
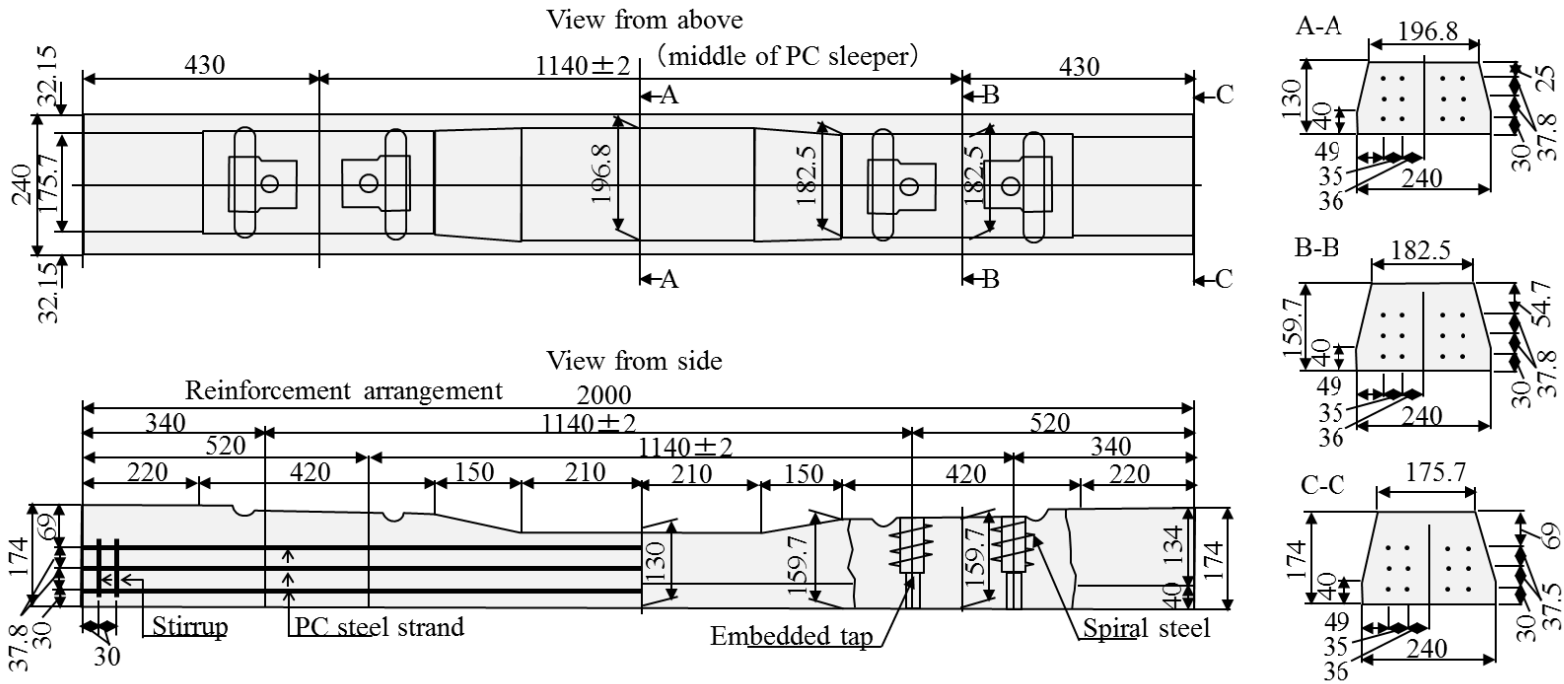

Figure 2. Cross section specifications of 3PR type sleeper 


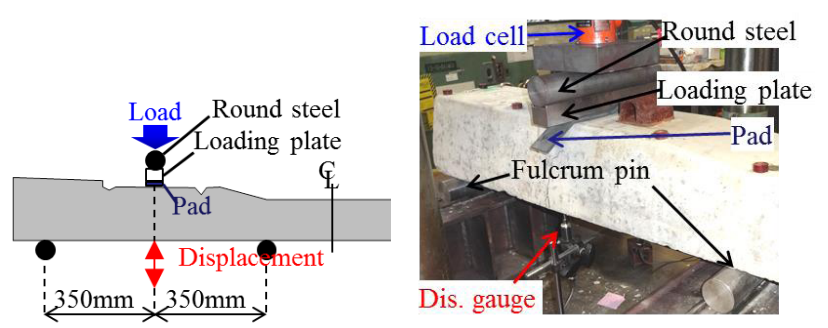

Figure 3. Outline of a bending test

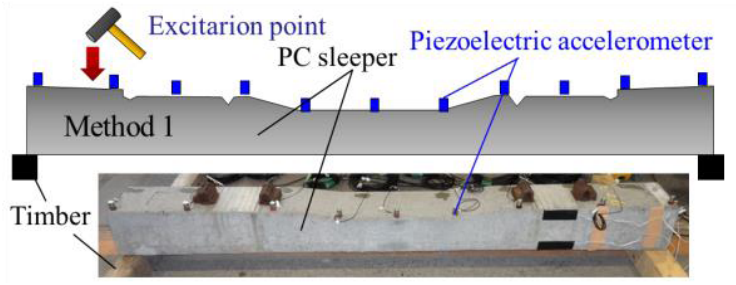

(a) Measurement method 1

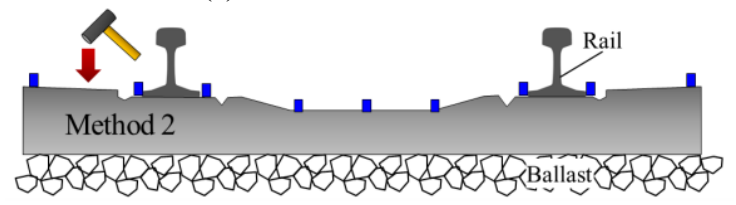

(b) Measurement method 2

Figure 4. Vibration measurement methods

\section{Test methods}

\subsection{Target PC sleepers}

Table 1 shows the list of PC sleepers targeted vibration measurements. Figure 2 shows cross section specifications of 3PR type PC sleeper as an example of the target sleepers. This study is focusing on 3PR (pretension) and 3PO (posttension) PC sleepers which are the standard applied in existing rail lines in Japan. The Bending test described later were also conducted for sleeper 1 and 7 shown as undamaged. PC sleeper 2-5 and 9-12 have different level actual damages (cracks and steel rod fracture) occurred in operation period, respectively. Based on the mode characteristics of these PC sleepers, the impact of the actual damage on the mode characteristic is clarified. It should be noted that PC sleepers 6 and 13 are the sleepers after loading at both rail positions and the middle position up to the ultimate state. Aside from these, in order to understand the variation due to the actual environment (ballast and rails), the vibration of the undamaged PC sleeper 14-19 were measured in the full-scale test rail line as described later.

\subsection{Bending test}

Figure 3 shows outline of a bending test. The test focusing on the cross section of rail positions of the PC sleeper 1 and 7 is compliant with JIS (Japanese Industrial Standards) E 1201 and 1202. To investigate the relation between the damage levels and mode characteristics, the loadings and vibration measurements were performed stepwise. It shows procedures of the bending test below. (0) Vibration measurement is carried out at undamaged state. (1) After loading and unloading the design proof load, the vibration is measured. (2) After loading and

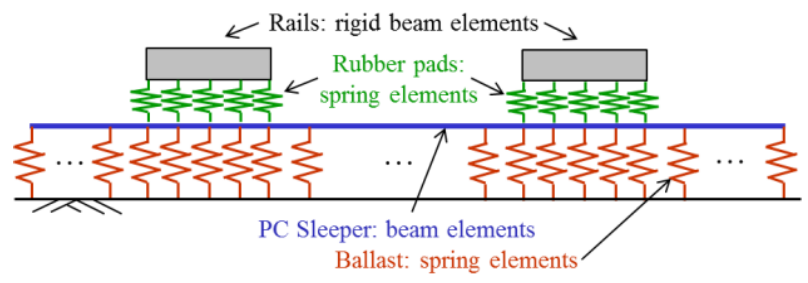

Figure 5. Numerical analysis model

unloading the cracking load, the vibration is measured.(3) After loading and unloading the 1.2 times cracking load, the vibration is measured. (4) After loading and unloading the ultimate load, the vibration is measured. Bending test targets were PC sleeper 1 and 7.

\subsection{Vibration measurements and identification}

Figure 4 shows the two types of vibration measurement methods adopted in this study. Measurement method 1 in Figure 4(a) is elastically supporting at both edges of PC sleeper by timbers. Measurement method 2 in Figure 4(b) is full-scale test line which is similar to the actual rail line environment. As shown in the figure, accelerometers are installed to the PC sleeper by epoxy adhesive through an insulating plate. To identify the modal properties of the PC sleeper, free vibration responses after impact excitation by the impulse hammer were measured by 11 (in method 1) or 9 (in method 2) piezoelectric accelerometers. Measured response at the accelerometer was recorded in laptop PC with $5 \mathrm{kHz}$ sampling via preamplifier and $\mathrm{A} / \mathrm{D}$ converter. Vibration characteristics were identified by ERA (Eigensystem Realization Algorithm) method. This method identifies the character matrix of linear time-invariant systems with the principles of minimal realization. Accuracy evaluation of the vibration characteristics was applied MAC (Modal Amplitude Coherence) value on the controllability. 40 degrees of freedom were set in order to identify the major modes of PC sleeper. In case that MAC value is 0.99 or more and mode damping ratio is 0.1 or less, it was judged to be a mode characteristic of the PC sleeper.

\subsection{Numerical analysis}

Figure 5 shows a numerical analysis model. Numerical analysis was carried out for validation of the identification results and sensitivity analysis. Crosssection of the PC sleeper model consisted of the A-A and B-B cross sections as shown in Figure 2. PC sleeper was modelled by beam elements with elastic modulus of 1.25 $\times 33.0 \mathrm{GPa}$ which was adjusted to the identification results as described later. Ballast was modelled as discrete supporting spring elements with design stiffness of $400 \mathrm{MN} / \mathrm{m}$ in the entire of supporting springs. As for the model for measurement method 1, supporting spring stiffness at both edges set $700 \mathrm{kN} / \mathrm{m}$, and the others were set 0 based on identification results. Rubber pads were modelled as spring elements with a stiffness of $60 \mathrm{MN} / \mathrm{m}$ in the entire of a rubber pad. In addition, the rail was considering only the mass by the rigid beam elements. 


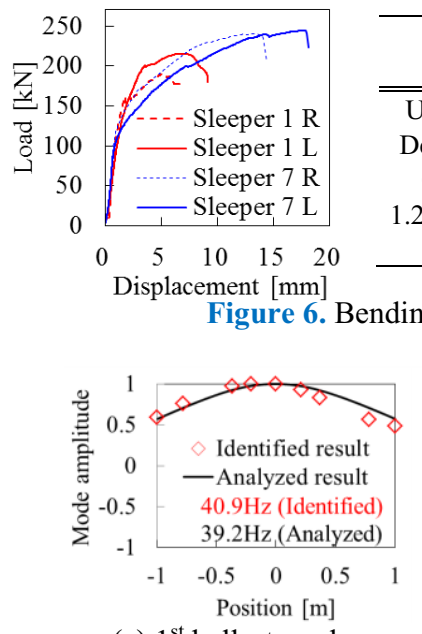

(a) $1^{\text {st }}$ ballast mode

\begin{tabular}{c|cccc}
\hline States & \multicolumn{4}{|c}{ Applied loads $[\mathrm{kN}]$} \\
& $1 \mathrm{R}$ & $1 \mathrm{~L}$ & $7 \mathrm{R}$ & $7 \mathrm{~L}$ \\
\hline \hline Undamaged & 0 & 0 & 0 & 0 \\
Design proof & 81 & 81 & 77 & 77 \\
Cracking & 111 & 108 & 124 & 126 \\
$1.2 \times$ cracking & 133 & 130 & 149 & 151 \\
Ultimate & 190 & 215 & 240 & 245 \\
\hline \multicolumn{4}{c}{ (R: right side, L: left side) }
\end{tabular}

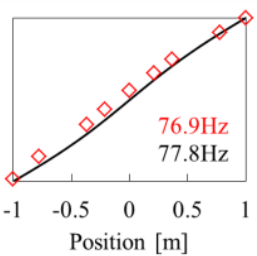

(b) $2^{\text {nd }}$ ballast mode

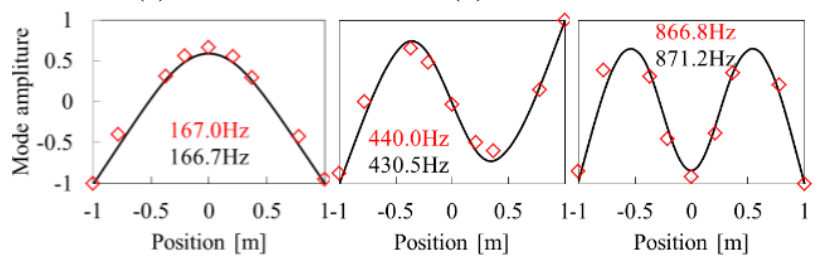

$\begin{array}{lll}\text { (c) } 1^{\text {st }} \text { sleeper mode } & \text { (d) } 2^{\text {nd }} \text { sleeper mode } & \text { (e) } 3^{\text {rd }} \text { sleeper mode }\end{array}$ Figure 7. Identified and analysed results (undamaged)

\section{Test results}

\subsection{Bending test results}

Figure 6 shows the applied load and the displacement of loading point in the bending test. It can be confirmed the gradually softening tendency when the load exceeds $110 \mathrm{kN}$ in which cracks occur.

\subsection{Identification results}

Figure 7 shows identified and analysed results of natural frequencies and vibration mode shapes of the 1st-3rd order modes. Identification results are based on the acceleration responses obtained by measurement method 1 for PC sleeper 1 (before loading). In addition, the natural frequencies and vibration mode shapes of the support springs mode are also shown in same figure. By estimating the support spring stiffness and concrete elastic modulus of numerical analysis model based on identification results, the numerical analysis model is able to reproduce the identification results (natural frequencies and mode shapes) of the measurement accurately.

\subsection{Relation between applied load and modal characteristics}

Figure 8 shows the relation between natural frequencies and applied loads. $1^{\text {st }}-3^{\text {rd }}$ mode characteristics (natural frequencies, modal damping ratios and vibration mode shapes) were identified based on the vibration measurements (method 1) which conducted after each loading. However, natural frequencies with the most high-impact were only shown in Figure 8. When the applied load exceeds 1.2 times of the cracking load
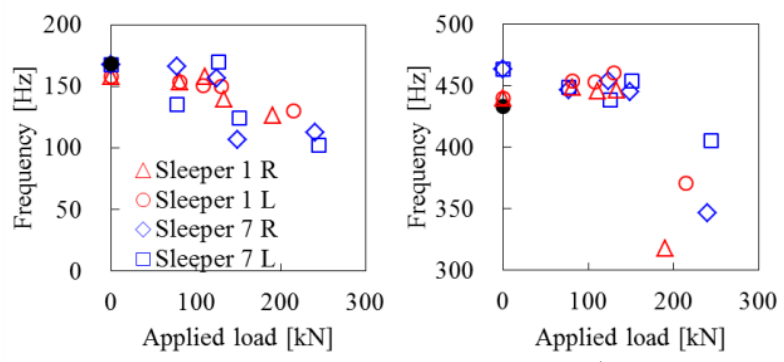
(a) $1^{\text {st }}$ mode
(b) $2^{\text {nd }}$ mode

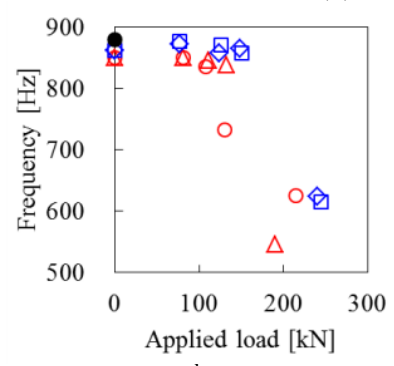

(c) $3^{\text {rd }}$ mode

Figure 8. Relation between the applied load and natural frequencies based on bending test

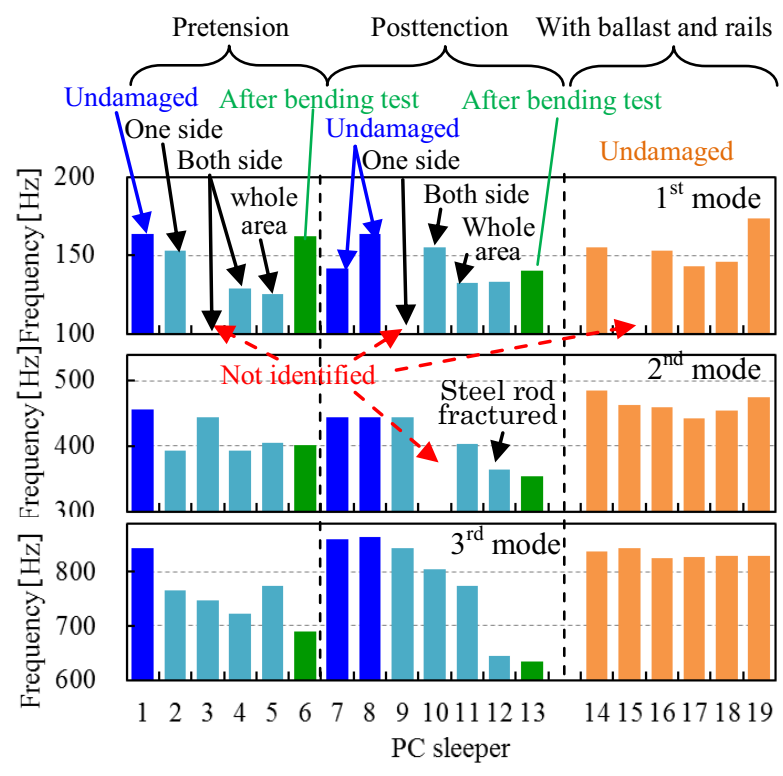

Figure 9. Relation between the actual damage and $3^{\text {rd }}$ mode natural frequency

(around $130 \mathrm{kN}$ ), it can be confirmed that the natural frequency of $1^{\text {st }}-3^{\text {rd }}$ modes begins to decrease. Further, the decrease amounts of natural frequency increase with the increased mode order. In particular the ultimate state of the $3^{\text {rd }}$ mode, the natural frequency was reduced more than $150 \mathrm{~Hz}(17 \%)$ in comparison with undamaged in all cases. It can be considered as due to the fact that the loading position (i.e., damaged position) coincides with the antinodes position of vibration mode shape. More detail of relation between the damage level and the amount of decrease in natural frequency including more high vibration modes based on the numerical analysis are shown in Appendix. It should be noted that the distinct features enough to available for abnormality detection in the mode damping ratios and the vibration mode shapes were not observed. 


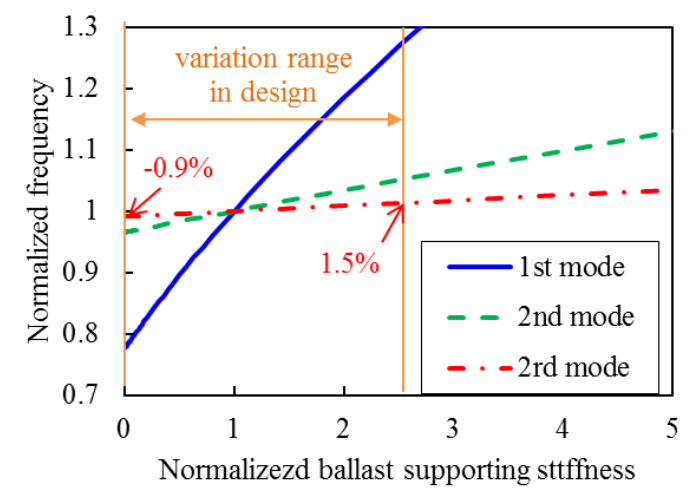

Figure 10. Relation between the ballast supporting stiffness and natural frequencies based on analysis

\subsection{Relation between actual damages and modal characteristics}

Figure 9 shows relations between actual damage and natural frequencies. Natural frequencies were identified based on the acceleration responses obtained by the measurement method 1 for PC sleeper $1-13$. Some $1^{\text {st }}$ or $2^{\text {nd }}$ mode natural frequencies could not be identified. Although the natural frequencies of the $2^{\text {nd }}$ mode tends to decrease as damaged PC sleepers, there are some case in which a natural frequency does not decrease significantly in spite of a serious damage. In contrast, $3^{\text {rd }}$ mode natural frequencies were certainly decreased in the damaged PC sleepers as compared with undamaged. Furthermore, it can be confirmed that a more serious damage causes a larger amount of decrease in $3^{\text {rd }}$ mode natural frequency.

\subsection{Relation between environments and modal characteristics}

Figure 9 also shows together the relation between natural frequencies and the actual environment (with ballast and rails). Natural frequencies were identified based on the acceleration response obtained by the measurement method 2 for undamaged PC sleepers 14-19. It should be noted that there are variations in the ballast supporting stiffness on the actual environment of the measurement method 2. As shown in Figure 9, despite only undamaged PC sleepers, the natural frequency of $1^{\text {st }}$ and $2^{\text {nd }}$ modes varies widely. On the other hand, $3^{\text {rd }}$ mode natural frequency has only few variation. It can be inferred that the $3^{\text {rd }}$ mode natural frequency is not almost affected by ballast supporting stiffness.

In order to investigate the effect of ballast support stiffness in more detail, a parametric analysis focusing on ballast supporting stiffness was performed. Figure 10 shows the relation between the ballast support stiffness and natural frequencies. Varying the support spring coefficients of the analysis model, the impact of the variation of ballast supporting stiffness on the natural frequencies of PC sleeper was examined analytically. The vertical axis indicates the natural frequency normalized by a result of calculation with $400 \mathrm{MN} / \mathrm{m}$ support spring, and the horizontal axis indicates ballast supporting

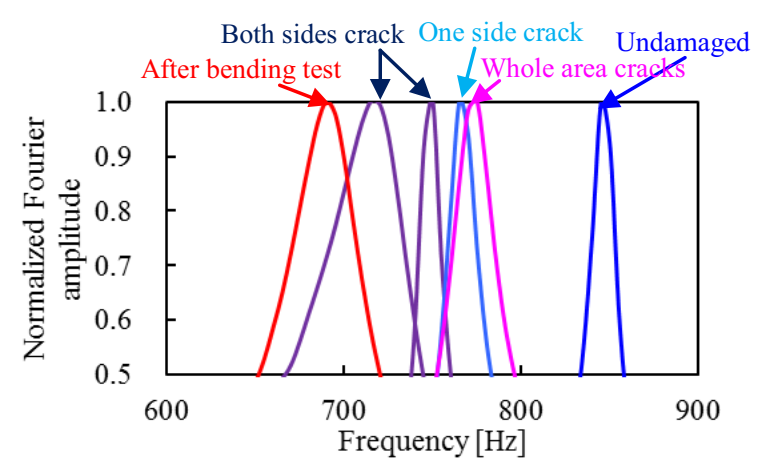

(a) Pretension system

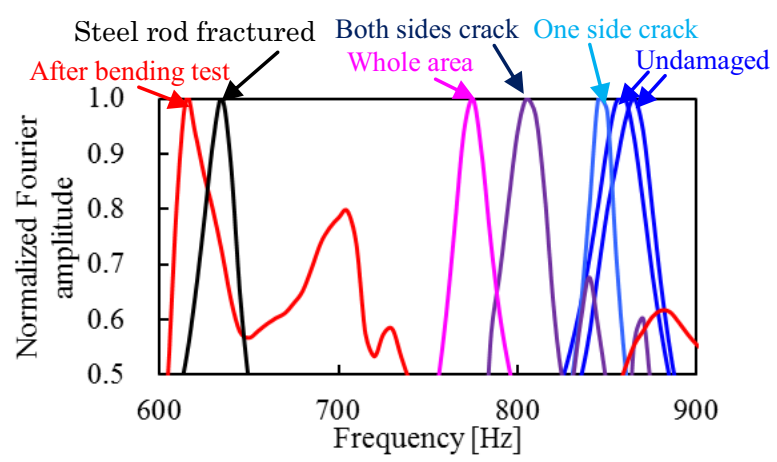

(b) Posttension system

Figure 11. Effect of actual damage on the predominant frequency of $3^{\text {rd }}$ mode

stiffness normalized by $400 \mathrm{MN} / \mathrm{m}$. Increasing the ballast supporting stiffness tends to increase the natural frequencies. However, as increasing the order of mode, the impact of ballast supporting stiffness decreases drastically. The same figure also shows the variation range of the ballast supporting stiffness considered in the Japanese design chord. It can be confirmed that the impact of ballast supporting stiffness on $3^{\text {rd }}$ mode natural frequency is confined from -0.9 to $1.5 \%$. Note that the rails have only few effects on the natural frequencies of PC sleeper due to a rubber pad places between a rail and PC sleeper.

From the above results and discussion, it can be confirmed that the $3^{\text {rd }}$ mode natural frequency is a suitable damage detection indicator which is not only clearly decreased by damages such like cracks but also be unaffected by variations of ballast supporting stiffness.

\subsection{Simplification of the measurement, installation and data processing}

Vibration measurements conducted in this study were aimed to understand the detailed of mode characteristics. Therefore, human and temporal costs are too excessive to subject to a lot of PC sleepers in actual railway field. In this section, aiming to the application on the routine patrol, damage detection accuracy based on single point measurement and simple data processing (peak frequency evaluation by Fourier transform) embeddable on a portable device are discussed.

Figure 11 shows the effect of the actual damage on the predominant frequency of $3^{\text {rd }}$ mode. Fourier spectrums were calculated based on measurement results of the point as shown in Figure 4(a) for single-point 


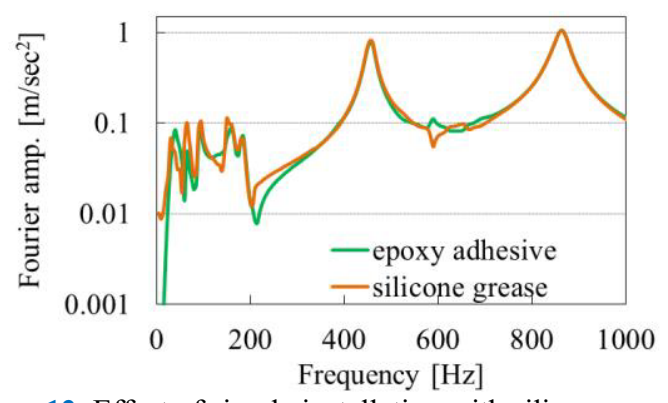

Figure 12. Effect of simple installation with silicone grease on Fourier spectrum

measurement. And the measurements were conducted on the PC sleeper 1-13. In addition, the spectrum was normalized by the maximum value of spectrum in the range of $600-1000 \mathrm{~Hz}$. Similarly to the multi-point measurement, it can be confirmed that a peak frequency is certainly decreased in accordance with the seriousness of the damage level.

Figure 12 shows the Fourier spectrum in the case of employment a simple installation with silicone grease as an installation method for reduction of the labour time. The measurement point was placed in the middle of PC sleeper. As shown in Figure 12, there are no remarkably differences on the spectrum due to the installation methods. Therefore, it can be confirmed that the measurement accuracy does not changed by employing the silicone grease. Employment of the silicone grease, it is possible to reduce the measuring operation of about 15 30 minutes per one point required in the case of the epoxy resin to within 5 minutes per one point.

\section{Conclusion}

In order to detect damages of PC sleepers that cannot be confirmed visually, a damage detection method based on the vibration mode of PC sleepers were discussed in this study. Obtained results are as follows.

(1) Natural frequencies of PC Sleeper begin to decrease in the case which more than 1.2 times of cracking load acts on the rail portion.

(2) $3^{\text {rd }}$ mode natural frequency is a suitable damage detection indicator which is not only clearly decreased by damages such like cracks but also be unaffected by variations of ballast.

(3) It is possible to high workability PC sleeper damage detection based on single point measurement by utilizing a predominant frequency of the $3 \mathrm{rd}$ modes and employment a installation with silicone grease.

To improve the reliability and generality of the knowledge obtained in the present study, it is necessary to accumulate a continuous test results in the future. Particularly, it is important to validate the detection accuracy of the PC sleepers with actual damage in the real environment.

\section{Appendix Damage impact analysis}

In order to understand the tendency for decrease in the natural frequency by cracks occurring at the bottom of

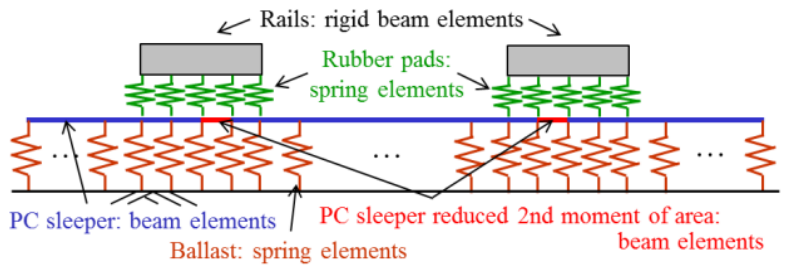

Figure 13. Analysis model with the damage by reducing the second moment of area

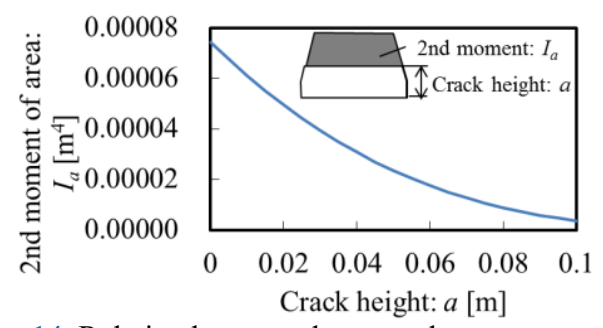

Figure 14. Relation between the secondary moment area and crack height

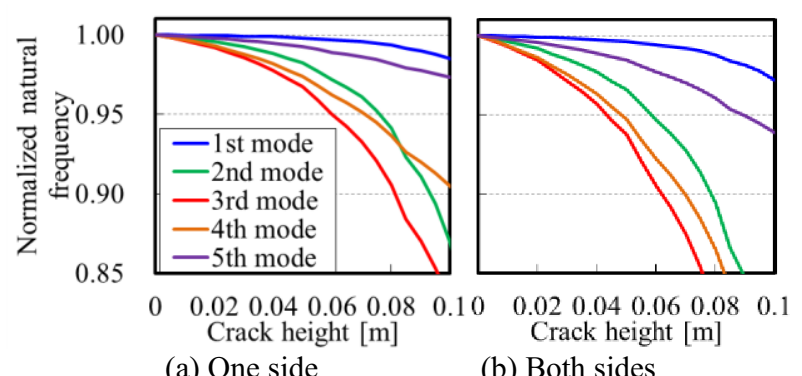

Figure 15. Relation between the crack height and natural frequencies (ballast supporting model)

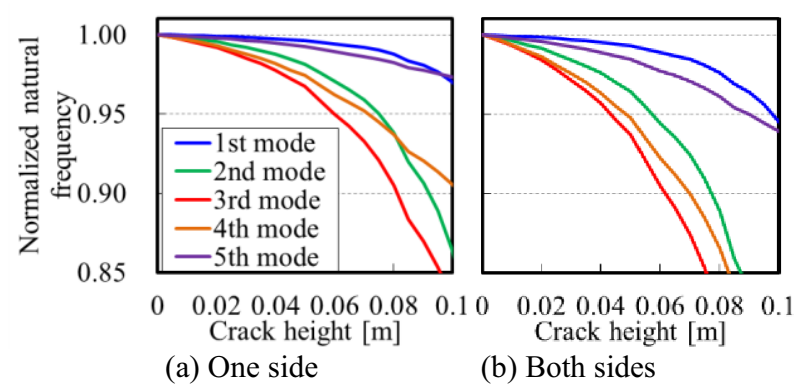

Figure 16. Relation between the crack height and natural frequencies (timber supporting model)

the rail position, a numerical analysis that reduces the second moment of area in the one of the PC sleeper elements in rail portion is conducted.

Figure 13 shows employment analysis model with the elements which reduced the second moment of area. Based on the vibration measurement results of this study, the elastic modulus of concrete is set to $1.25 \times 33.0 \mathrm{GPa}$, ballast supporting stiffness is set to $0.3 \times 400 \mathrm{MN} / \mathrm{m}$. Figure 14 shows a relation between the secondary moment area and crack height. Here, in order to modelling the damage due to crack simply, the following two assumptions are introduced. One is that cracks occur from the bottom face. Another is that the cross-section of up to crack height is not resistance against bending.

Figure 15 shows the relation between the crack height (of one side or both sides at the bottom of rail positon) and natural frequencies which are normalized by 
undamaged results. These results were obtained by the analysis based on ballast supporting models. From the figure, it can be confirmed that the $3^{\text {rd }}$ mode natural frequency has a high sensitivity to cracks in cross section of rail position comparing with not only $1^{\text {st }}$ and $2^{\text {nd }}$ mode but also higher order mode such like $4^{\text {th }}$ and $5^{\text {th }}$. When the crack of the height of $70 \mathrm{~mm}$ from the bottom (crack up to half of the B-B cross section) occurs, $3^{\text {rd }}$ mode natural frequency decreases approximately $5 \%$ on one side crack, and $12 \%$ on both sides crack.

Figure 16 shows analysis results in the case which the supporting conditions of analysis model changed to timbers supports (elastic support in both edges). The stiffness of support springs at both edges is $700 \mathrm{kN} / \mathrm{m}$ based on the vibration measurements described above. Since a large amount of decrease in $1^{\text {st }}$ mode natural frequency in the case of the timber support comparing with the ballast support, the measurement method employing timber support tends to excessively well evaluate the damage detection accuracy as compared with the ballast support in $1^{\text {st }}$ mode. However, in any other mode, the relation between the crack height and the decrease amount of natural frequency does not almost change by the ballast support and the timber support. From these results, it can be confirmed that the measurement methods (timber supporting) employed in this study is able to evaluate the damage detection accuracy of $2^{\text {nd }}-5^{\text {th }}$ mode at the real environment (ballast supporting) approximately.

\section{References}

1. H., Wakui, H. Okuda, A Study on Limit State Design Method for Prestressed Concrete Sleepers. In PROCEEDINGS-JAPAN SOCIETY OF CIVIL ENGINEERS, 35-54 (1997).

2. A. Remennikov, S. Kaewunruen, Experimental investigation on dynamic railway sleeper/ballast interaction. Experimental Mechanics, 46(1), 57-66 (2006).

3. Barke, W.K. Chiu, Structural health monitoring in the railway industry: a review. Structural Health Monitoring, 4(1), 81-93 (2005).

4. .N. Juang, R.S. Pappa, An eigensystem realization algorithm for modal parameter identification and model reduction. Journal of guidance, control, and dynamics, 8(5), 620-627 (1985).

5. Railway Technical Research Institute. Design Standards for Railway Structures and Commentary (Concrete Structures): Railway Technical Research Institute; (2007).

6. A. Aikawa, F. Urakawa, A. Kono, A. Namura, Sensing sleeper for dynamic pressure measurement on a sleeper bottom induced by running trains, Railway Engineering 2009, CD-ROM, University of Westminster, London, UK, (2009). 